American Journal of Applied Sciences 6 (7): 1352-1358, 2009

ISSN 1546-9239

(C) 2009 Science Publications

\title{
Coating and Encapsulation of Nanoparticles using Supercritical Antisolvent
}

\author{
${ }^{1}$ G.H. Chong, ${ }^{1}$ R. Yunus, ${ }^{1}$ N. Abdullah, ${ }^{1}$ T.S.Y. Choong, and ${ }^{2}$ S. Spotar \\ ${ }^{1}$ Department of Chemical and Environmental Engineering, Faculty of Engineering, \\ University Putra Malaysia, 43400 UPM, Serdang, Selangor, Malaysia \\ ${ }^{2}$ Faculty of Engineering and Computer Science, The University of Nottingham, \\ Malaysia Campus, 43500 Semenyih, Selangor, Malaysia
}

\begin{abstract}
Problem statement: Literature on the production of nanoparticles using supercritical fluids is substantial, but comparatively much less for nanoencapsulation. Approach: In this study, a modified Supercritical Anti Solvent (SAS) apparatus was fabricated for use in the production of nanoparticles using carbon dioxide as the supercritical fluid (SCF). SAS technique involves precipitation of solids from liquid solution under supercritical antisolvent-induced condition. Production of nanoparticles using SAS was investigated using 2 types of model solutes: Fume silica and acetaminophen which represent a model of water insoluble (inorganic) material and water soluble material respectively. The morphology and characteristics of nanoparticles produced were assessed. Results: The fume silica had been coated and $50 \mathrm{~nm}$ diameter of nanoencapsulated acetaminophen had been produced. Conclusion: The results had revealed that both water insoluble and soluble substrates can be coated and encapsulated successfully in polymer by the SAS coating process.
\end{abstract}

Key words: Coating, encapsulation, supercritical anti solvent, water insoluble material, water soluble material

\section{INTRODUCTION}

The interest in preparation and application of nanometer size materials is increasing since they exhibit properties of great industrial interest. During the past 2 decades, a number of SCF particles formation techniques have been developed, such as Rapid Expansion Supercritical Solution (RESS), Gas Anti Solvent (GAS), Supercritical Anti Solvent (SAS), solution enhanced dispersion by supercritical fluids $(\mathrm{SEDS})^{[1,2]}$. The formation of a single supercritical phase is the key step for the successful production of nanoparticles $^{[3,4]}$. In SAS, $\mathrm{CO}_{2}$ is typically used as the SCF, which also acts as an anti solvent for polymersolute solution. In a typical SAS operation, a polymersolute is dissolved in a liquid solvent to form a solution. The solution is then sprayed into a chamber which has been preconditioned with $\mathrm{SCF}$, causing rapid contact between the two media. This generates supersaturated condition, resulting in fast nucleation and growth and consequently creates smaller particles ${ }^{[5]}$. A special advantage of this technique is its adaptability for continuous operations, which is important for large- scale mass production of particles. This realization has led to the present investigation on particle formation technologies in particular those within range of nanometer in size.

The problems related to solvent and surfactant removal from the drug-polymer composite product ${ }^{[6]}$, harsh operating conditions and time consuming methods ${ }^{[7-10]}$ can be addressed accordingly by using SAS. Unlike conventional technique such as solvent evaporation method, SAS operating condition provide the flexibilities in controlling the size of particles that span from micro to nanometers.

The main objective of this study is to synthesize nano-composites (solute-polymer) using SAS technique. Two types of samples, fume silica and acetaminophen were used with copolymer of acrylate and methacrylate as the coating polymer. Fume silica was used as the solute in the coating process which the solute does not dissolve in the solvent. Meanwhile, acetaminophen was used as a model solute for the encapsulation process. In this process, acetaminophen (solute) dissolves in solvent and in order for encapsulation to take place, both the solute and polymer must be precipitated.

Corresponding Author: R. Yunus, Department of Chemical and Environmental Engineering, Faculty of Engineering, University Putra Malaysia, 43400 UPM, Serdang, Selangor, Malaysia

Tel: +60386567120 Fax: +6086567021 


\section{MATERIALS AND METHODS}

Eudragit RL100 (JJ Degussa, USA), a copolymer of acrylate and methacrylate, with an average molecular weight of $150000 \mathrm{~g} \mathrm{moL}^{-1}$ was used as polymer coating material. Fume silica (Aerosil 200, Degusa, USA) was used as a model for coating process whereas acetaminophen (supplied by Faculty of Medicine and Health Sciences, UPM) for encapsulation process. Purified grade of $\mathrm{CO}_{2}, 99.98 \%$ purity (MOX, Malaysia) was used as the SCF, while HPLC grade acetone was used as the solvent (Sigma, UK).

The experiments were performed using a SAS system that was designed and fabricated in-house SAS system (Fig. 1). It consisted of SCF delivery, feed delivery and precipitation vessel with a capacity of $6 \mathrm{~L}$ and particles collector. The temperature of the system was controlled by a water-bath through out the experiment. Liquefied $\mathrm{CO}_{2}$ was delivered to the vessel using a high pressure pump.

This silica coating process had been studied by ${ }^{[5]}$. At that study, pressure of the whole system needs to be fully released before collecting the particles. Therefore in this study an external particles collector (Fig. 2) was designed and fixed at the bottom of precipitation vessel. The size of inlet was designed in order to have a turbulence condition when $\mathrm{SCCO}_{2}$ entering the particles collector so that the particles were evenly distributed on the surface of membrane filter. An additional needle valve was installed just after the precipitation vessel with the purpose to maintain the pressure of precipitation vessel by closing the valve while collecting the particles. Subsequent experiment could be run after placing the new membrane in the particles collector.

A polymer solution was prepared by dissolving $0.8 \mathrm{~g}$ of Eudragit solution in $100 \mathrm{~mL}$ of acetone. Silica $(0.8 \mathrm{~g})$ was suspended in the polymer solution using ultrasonicator $(40 \mathrm{KHz})$ to break up any agglomerates in the polymer silica-acetone suspension.

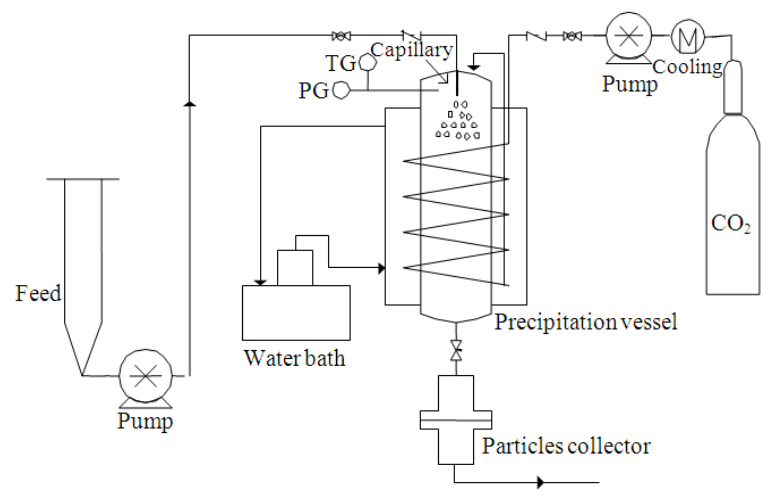

Fig. 1: Schematic diagram of SAS system
The temperature and pressure were set to be constant throughout the experiment. The system was set and preconditioned at required operating condition (Table 1). When steady state conditions were reached, the polymer-solute suspension was delivered by a high

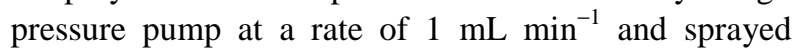
through a capillary nozzle (internal diameter $150 \mu \mathrm{m}$ ) into the precipitation vessel. The spraying lasted for about $90 \mathrm{~min}$ and followed by another $30 \mathrm{~min}$ for settling step. After that, the $\mathrm{CO}_{2}$ was further supplied to the vessel for a period of $2 \mathrm{~h}$ to allow a complete flushing and removal of residual organic solvent. When the cleaning step was completed, the high-pressure vessel was slowly depressurized and samples were collected for characterization. The experimental parameters were shown in Table 1.

\section{Characterization of samples:}

Field emission scanning electron microscope (FESEM): FE-SEM, model FEI Quanta 200 was used to observe the morphological of the nanoparticles. Sample was sputter coated for 20 s with gold to make the surface conductive without compromising the fine surface microstructure.

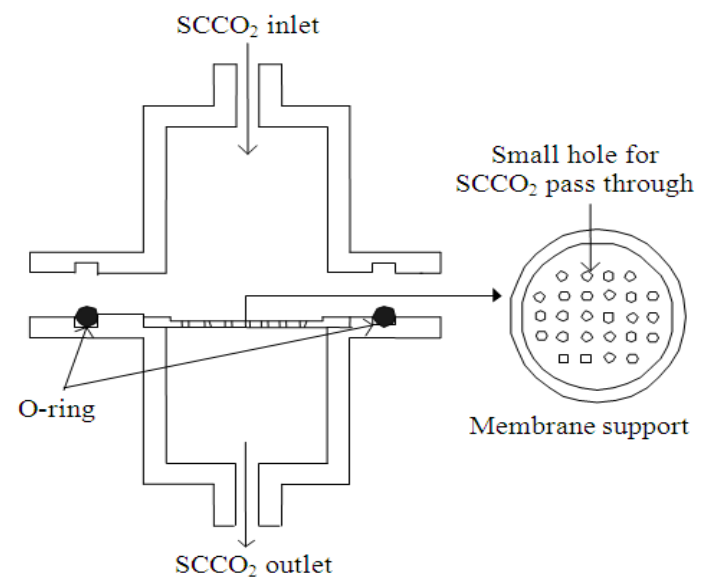

Fig. 2: Diagram of particles collector used in SAS system

Table 1: Experimental parameters in SAS coating process

\begin{tabular}{|c|c|c|c|c|}
\hline \multirow[b]{2}{*}{ Experiment } & \multicolumn{4}{|l|}{ Parameters } \\
\hline & $\begin{array}{l}\text { Polymer } \\
\text { concentration } \\
\left(\mathrm{g} \mathrm{mL}^{-1}\right)\end{array}$ & $\begin{array}{l}\text { Targeted } \\
\text { solute } \\
(\mathrm{g})\end{array}$ & $\begin{array}{l}\text { Pressure } \\
\text { (bar) }\end{array}$ & $\begin{array}{l}\text { Temperature } \\
\left({ }^{\circ} \mathrm{C}\right)\end{array}$ \\
\hline Coating of silica (run 1) & 0.008 & 0.4 & 86 & 35 \\
\hline Coating of silica (run 2) & 0.004 & 0.4 & 76 & 35 \\
\hline $\begin{array}{l}\text { Encapsulation of } \\
\text { acetaminophen }\end{array}$ & 0.012 & 0.1 & 100 & 35 \\
\hline
\end{tabular}


Energy dispersive X-ray (EDX): The sample was analyzed based on the element compound by EDX. The tension used was $10 \mathrm{kV}$ and it was the integrated function of FESEM.

In-vitro drug release: The $50 \mathrm{mg}$ of nude acetaminophen and processed acetaminophen were placed separately in $100 \mathrm{~mL}$ Phosphate Buffered Saline (PBS) solution 0.1M, pH 7.4. The mixture was shaken at $50 \mathrm{rpm}, 37^{\circ} \mathrm{C}$. At scheduled time intervals, $1.0 \mathrm{~mL}$ of PBS was collected from the solution mixture and immediately replenished with fresh PBS to maintain the original volume.

High Performance Liquid Chromatography (HPLC): The content of released acetaminophen into the PBS solution was determined by HPLC (Shimadzu). Column hypersil gold C18 was used and absorption at UV $267 \mathrm{~nm}$ was recorded. Mobile phase was a mixture of water and methanol at the ratio of 80:20 to which ammonium acetate was added to make final concentration of $10 \mathrm{mM}$ was used. The mobile phase was adjusted to $4.0 \mathrm{pH}$ with acetic acid ${ }^{[12]}$. The flow rate was set at $1.0 \mathrm{~mL} \mathrm{~min}^{-1}$ at $30^{\circ} \mathrm{C}$.

Fourier Transform-Infrared (FT-IR) spectroscopy: FTIR spectrometry (Perkin Elmer, model spectrum 100) was used to determine the chemical composition of samples before and after the treatment. The sample was placed in the sample holder directly which was on the surface of diamond crystal.

\section{RESULTS AND DISCUSSION}

Coating of silica: In this research, the formation of nano-composites from two types of solutes using Eudragit polymer was investigated. Fume silica nanoparticles were chosen to evaluate the effectiveness of coating the water insoluble material using the SAS system. The electron micrograph in Fig. 3 shows the morphology and size of the silica particles as chained agglomerated structure. From the higher magnification micrograph, the size of uncoated silica particle was estimated to be within a range of $16-30 \mathrm{~nm}$.

Figure 4 shows the SEM micrograph of the processed hydrophobic silica nanoparticles with Eudragit polymer. Morphology of these nanoparticles was quite different from that of uncoated. Judging from morphological changes and size enlargement of silica in Fig. 4, the polymer may have coated the surface of the nanoparticles during the SAS process, forming a thin layer coating. The Energy Dispersive X-ray (EDX) analysis confirmed that this size increment was due to carbon content contributed by the polymer (Table 2 ).
Table 2: The EDX analysis of elemental content (excluding gold coated)

\begin{tabular}{llll}
\hline Sample & Wt \% carbon & Wt \% oxygen & Wt \% silicon \\
\hline Pure silica & 0 & 58.9 & 41.0 \\
Coated of silica (Run 1) & 11.7 & 54.6 & 33.6 \\
Coated of silica (Run 2) & 27.2 & 47.9 & 24.7 \\
\hline
\end{tabular}

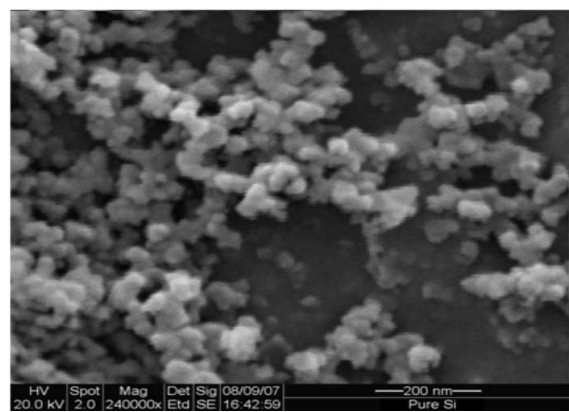

Fig. 3: FESEM image for uncoated silica

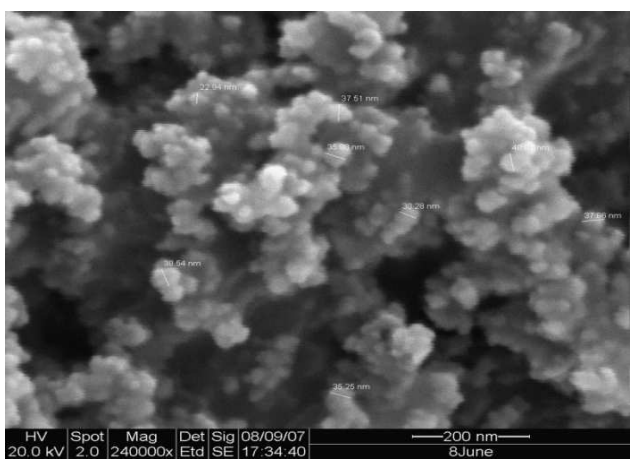

Fig. 4: FESEM image for processed silica, 86 bars, $35^{\circ} \mathrm{C}$ (run 1 )

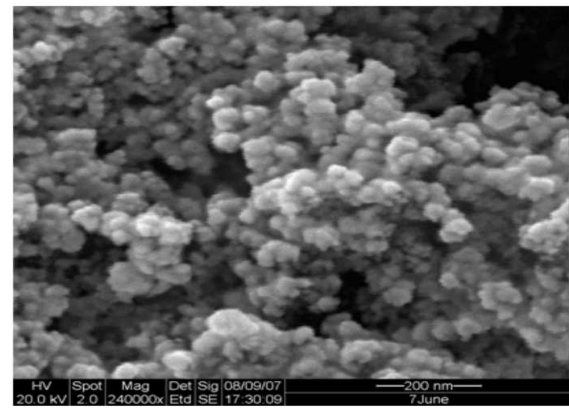

Fig. 5: FESEM image for processed silica, 76 bars, $35^{\circ} \mathrm{C}$ (run 2)

The effect of operating parameters such as polymer concentration and ratio of polymer to nanoparticles was investigated in coating of the silica nanoparticles. Figure 5 shows an FESEM image for the coated silica (run 2) at 76 bars, $35^{\circ} \mathrm{C}$ using $0.4 \mathrm{~g} 100 \mathrm{~mL}^{-1}$ polymer concentrations and 1:2 polymers to nanoparticles ratio. 


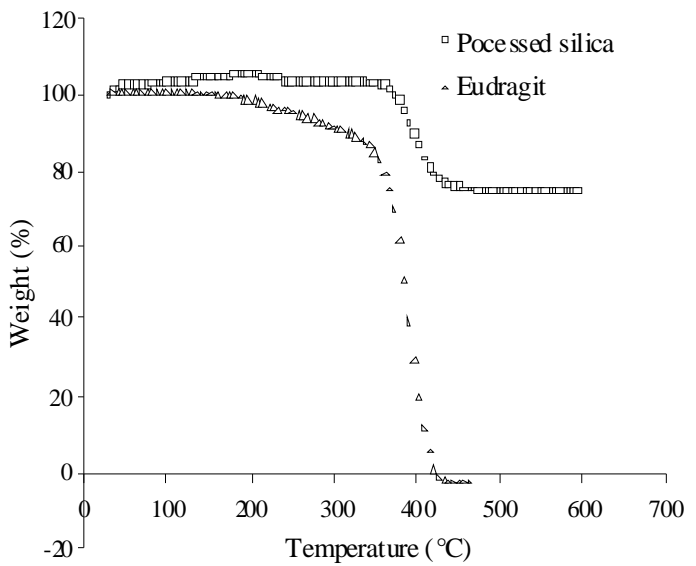

Fig. 6: TGA diagrams of (a) processed silica and (b) coating material (Eudragit)

The morphology of silica nanoparticles was different to that shown in the Fig. 4. Qualitatively, the polymer was found to coat the silica nanoparticles at a more uniform manner at higher pressure without the appearance of thin layer polymer. The silica particles was polymer coated as confirmed by the increment of carbon content (contributed by the polymer coating) from the EDX analysis.

Figure 6 shows the TGA curves for the pure polymer (Eudragit) and processed silica. At the beginning, the trend of the weight loss was similar for both Eudragit and processed silica. Pure Eudragit experienced about $10 \%$ weight loss at $350^{\circ} \mathrm{C}$ primarily due to the moisture evaporation and was completely burned off at $420^{\circ} \mathrm{C}$. On the other hand, the processed silica comprised of $33 \%(\mathrm{w} / \mathrm{w})$ Eudragit exhibits a much higher onset degradation temperature of $400^{\circ} \mathrm{C}$ as compared to $320^{\circ} \mathrm{C}$ for pure Eudragit. This indicates that the polymer in processed silica does not exist in pure form, rather it is physically coated/attached onto the silica. This has resulted in a more thermally stable material, with higher onset temperature. However, above $450^{\circ} \mathrm{C}$ all the remaining Eudragit presumably coated onto the silica were completely burned off, while the remaining silica was still stable since the melting point of silica is $1700^{\circ} \mathrm{C}$.

Figure 7 shows the results for FTIR analysis. The spectrum of Eudragit which is a copolymer of acrylate and methacrylate is shown in Fig. 7b. The peak at $2951.58 \mathrm{~cm}^{-1}$ is the transmittance of the alkyl groups while the peak at $1724.39 \mathrm{~cm}^{-1}$ is contributed by carbonyl group. The spectrum of silica (Fig. 7a) shows a major peak at $1067.20 \mathrm{~cm}^{-1}$, which is $\mathrm{Si}-\mathrm{O}$ stretching vibration. It is observed that only few peaks from polymer spectrum appear on the processed silica.

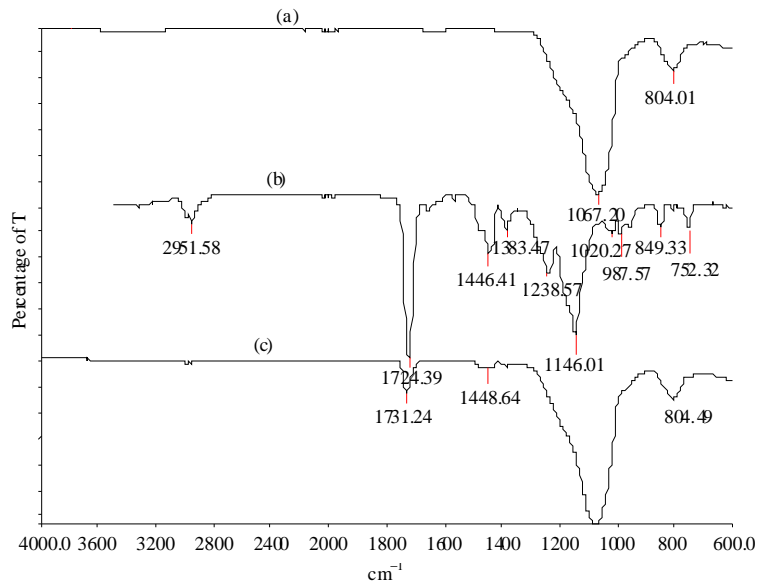

Fig. 7: FTIR spectra for coating process. (a): Silica; (b): Eudragit; (c): Processed silica

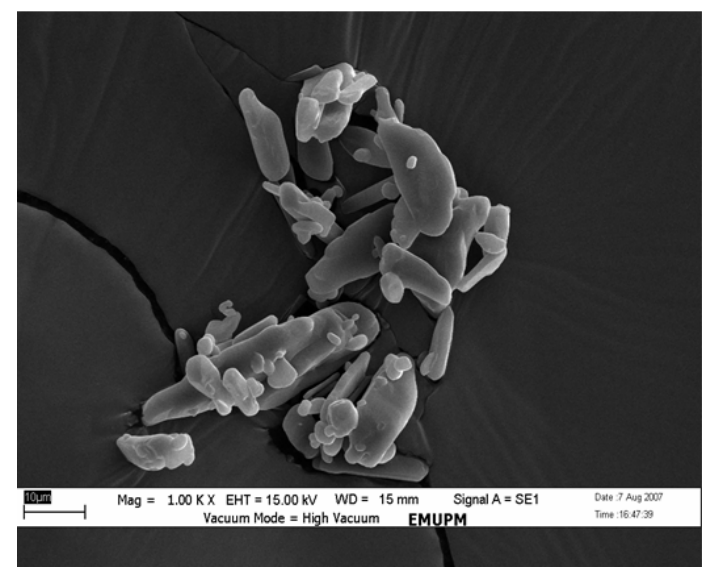

Fig. 8: SEM for acetaminophen

This may indicate that, the Eudragit was coated to the silica but only formed a very thin layer coating. Since, there is no additional peak appears on the processed silica spectrum, it may be concluded that the coating of silica was mainly physical coating. This observation is similar to Wang et al. ${ }^{[5]}$.

Encapsulation of acetaminophen: The use of SAS technique in encapsulation was also explored. Acetaminophen was used as a model drug and Eudragit as the coating polymer. The experiment was performed using the same set up as the silica substrate.

The electron micrographs in Fig. 8 and 9 show the results for nude and processed acetaminophen respectively. Figure 8 and 9 show that the nude acetaminophen is irregular in shape while the shape of processed acetaminophen is mainly spherical. From the scale bar shown in Fig. 9, the particles size is estimated to be about $50 \mathrm{~nm}$. 
Figure 10 shows the TGA curves of Eudragit, processed acetaminophen and nude acetaminophen. Initially the profile of weight loss for the processed acetaminophen follows the nude acetaminophen profile of which indicates that the Eudragit does not appear in pure form. If it appears in pure form, the profile for the processed acetaminophen initially would have resembled the Eudragit. However, the second portion of the TGA spectrum follows the profile of pure Eudragit which indicate that the processed acetaminophen is no longer a pure acetaminophen. The processed acetaminophen was already encapsulated with Eudragit. However, at $430^{\circ} \mathrm{C}$ most of the Eudragit were thermally decomposed, leaving only a small amount of thermally stable material (14\%) which could be made of chemically bonded acetaminophen and Eudragit. This result also proves that the encapsulation of acetaminophen with Eudragit RL100 by SAS is mainly a physical process.

The spectra of processed acetaminophen, nude acetaminophen and pure polymer (Eudragit RL100) are shown in Fig. 11. The spectrum for the processed acetaminophen is similar to Eudragit because $92.3 \%$ of the processed acetaminophen comprise of Eudragit. However, by comparing the spectra, the peak at $1513.25 \mathrm{~cm}^{-1}$ which is the peak for the aromatic nitro compound, from the nude acetaminophen, appears on the processed acetaminophen spectrum. This proves the existence of acetaminophen in the processed acetaminophen since there is no such functional group from Eudragit.

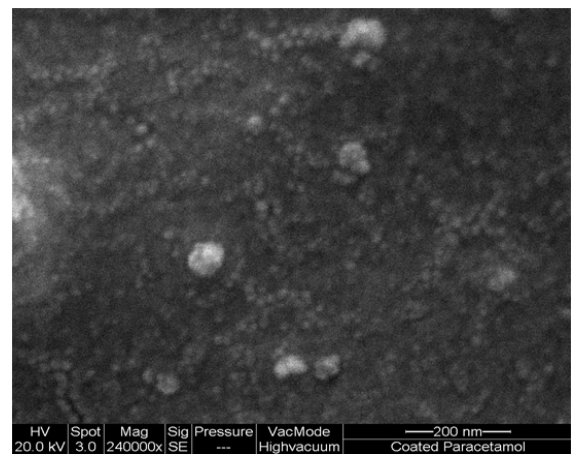

Fig. 9: SEM for processed acetaminophen

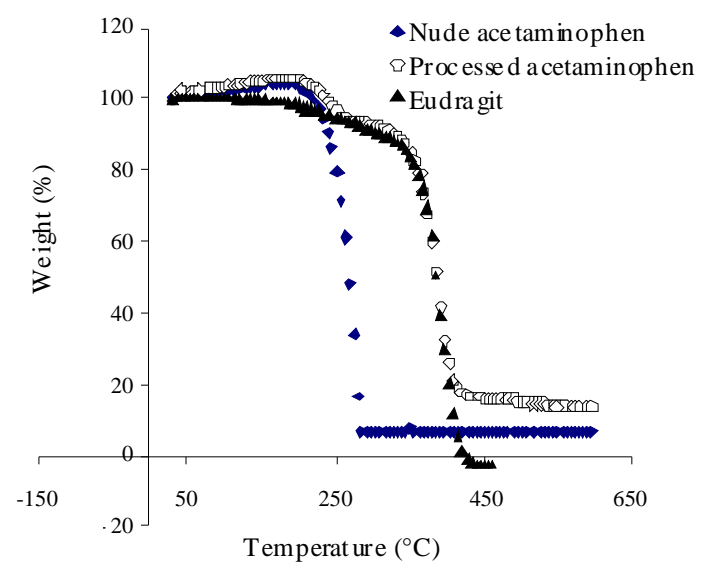

Fig. 10: TGA diagrams of (a): Nude acetaminophen; (b): Processed acetaminophen and (c): Eudragit

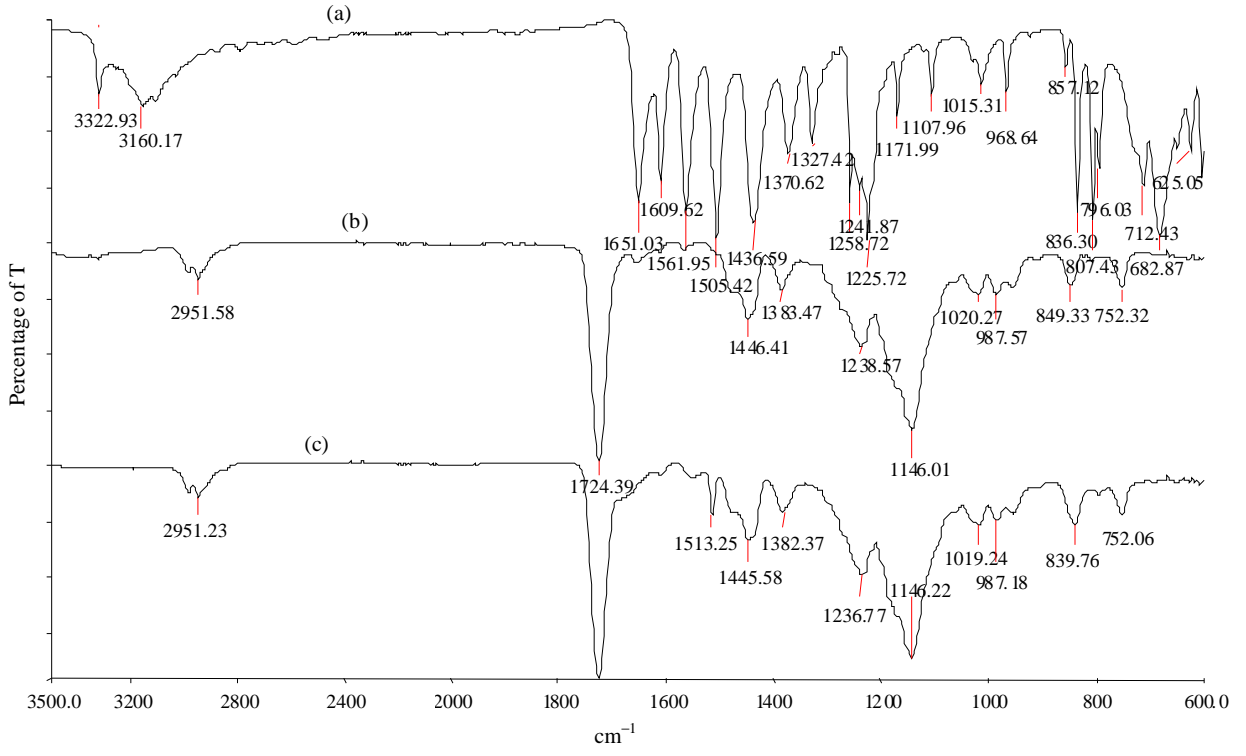

Fig. 11: FTIR spectra for encapsulation process, (a): Nude acetaminophen; (b): Eudragit and (c): Processed acetaminophen 


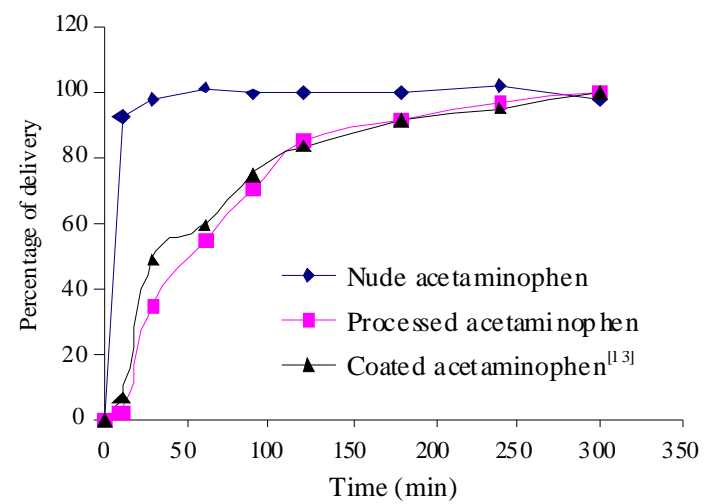

Fig. 12: An in vitro release profile of nude and processed acetaminophen

The in vitro release test was also carried out and the release profiles for the nude and processed acetaminophen are depicted in Fig. 12. The release of processed acetaminophen was time delayed due to the polymer layer which acted as a barrier to the drug release compared to the nude acetaminophen. Therefore, it could be concluded that acetaminophen was well encapsulated since there is no burst release observed from Fig. 12. Baykara and Karatas ${ }^{[13]}$, used the coacervation phase separation technique for producing tablet microcapsule of acetaminophen with Eudragit RL100 and observed similar release profile to this study (Fig. 12). Therefore, it can be concluded that the SAS is an effective technique to encapsulate acetaminophen for controlled drug release. However, this result was contradicting with Wang et al. ${ }^{[14]}$ which found that they were unable to encapsulate hydrocortisone in co-precipitation process. This might be due to improper selection of operating conditions.

\section{CONCLUSION}

Coating and encapsulation of solute with polymer into nanoparticles using the SAS coating technique were investigated in this study. The results have revealed that water insoluble and soluble substrates can be coated and encapsulated successfully in polymer by the SAS coating process. However, broader ranges of operating parameters are being studied while this study was prepared. The external particles collector is being used for collecting the nanoparticles and this step might lead to the possibility of using SAS as a continuous process.

\section{ACKNOWLEDGEMENT}

The researchers would like to thank Dr. S. Johnson from Faculty of Medicine and Health Sciences, UPM and staffs from Faculty of Science and Food Technology, UPM for their help and opinion.

\section{REFERENCES}

1. Reverchon, E. and R. Adami, 2006. Nanomaterials and supercritical fluids. J. Supercritic. Fluids, 37: 1-22. DOI: 10.1016/j.supflu.2005.08.003

2. Yeo, S.D. and K. Erdogan, 2005. Formation of polymer particles with supercritical fluids: A review. J. Supercrtic. Fluids, 34: 287-308. DOI: 10.1016/j.supflu.2004.10.006

3. Reverchon, E., G. Caputo and I. De Marco, 2003. Role of phase behavior and atomization in thesupercritical antisolvent precipitation. Ind. Eng. Chem. Res., 42: 6406-6414. DOI: 10.1021/ie0302138

4. Reverchon, E., I. De Macro and E. Torino, 2007. Nanoparticles production by supercritical antisolvent precipitation: A general interpretation. J. Supercritic. Fluids, 43: 126-138. DOI: 10.1016/j.supflu.2007.04.013

5. Wang, Y., R.N. Dave and R. Pfeffer, 2004. Polymer coating/encapsulation of nanoparticles using a supercritical anti-solvent process. J. Supercritic. Fluids, 28: 85-99. DOI: 10.1016/S0896-8446(03)00011-1

6. Torché, A.M., H. Jouan, P.L. Corre, E. Albina, R. Primault, A. Jestin and R.L. Verge, 2000. Ex vivo and in situ PLGA microspheres uptake by pig ileal Peyer's patch segment. Int. J. Pharm., 201: 15-27. DOI: $10.1016 / \mathrm{S} 0378-5173(00) 00364-1$

7. Hans, M.L. and A.M. Lowman, 2002. Biodegradable nanoparticles for drug delivery and targeting. Curr. Opin. Solid State Mater. Sci., 6: 319-327. DOI: 10.1016/S1359-0286(02)00117-1

8. Feng, S.S. and G. Huang, 2001. Effect of emulsifier on the controlled release of paclitaxel (Taxol) from nanospheres of biodegaradable polymers. J. Controll. Release, 71: 53-69. DOI: 10.1016/S0168-3659(00)00364-3

9. Carino, G.P., J.S. Jacob and E. Mathiowitz, 2000. Nanosphere based oral insulin delivery. J. Control. Release, 65: 261-269. DOI: 10.1016/S01683659(99)00247-3

10. Kwon, H.Y., J.Y. Lee, S.W. Choi, Y. Jang and J.H. Kim, 2001. Preparation of PLGA nanoparticles containing estrogen by emulsification-diffusion method. Colloids Surf. A. Physicochem. Eng. Aspects, 182: 123-130. DOI: 10.1016/S0927-7757(00)00825-6 
11. Lai, M.K. and C.C. Tsiang, 2004. Encapsulating acetaminophen into poly (L-lactide) microcapsules by solvent-evaporation technique in an $\mathrm{O} / \mathrm{W}$ emulsion. J. Microencapsulat., 21: 307-316. DOI: 10.1080/02652040410001673928

12. Gopinath, D., D. Ravi, B.R. Rao, S.S. Apte, D. Renuka and D. Rambhau, 2004. Ascorbyl palmitate vesicles (Aspasomes): formation, characterization and applications. Int. J. Pharm., 271: 95-113. DOI: 10.1016/j.ijpharm.2003.10.032
13. Baykara, T. and A. Karatas, 1993. Preparation of acetaminophen microcapsules by coaservation phase separation method. Drug Develop. Ind. Pharm., 19: 587-601. DOI: $10.3109 / 03639049309062968$

14. Wang, Y., J. Yang, R. Pfeffer, R. Dave and B. Michniak, 2006. The application of a supercritical antisolvent process for sustained drug delivery Powder Technol., 164: 94-102.

DOI: 10.1016/j.powtec.2006.03.004 